\title{
TRACHEOSTOMY IN SOKOTO, NORTH WESTERN NIGERIA: A TEN YEARS EXPERIENCE.
}

Aliyu D, Iseh KR, AbdullahI M, AmuttA SB, YikawE SS

Department of Ear, Nose and Throat, Usmanu Danfodiyo University Teaching Hospital, Sokoto, Nigeria

Correspondence: Dr Aliyu Jiya Daniel

Department of Ear, Nose and Throat (ENT), Usmanu Danfodiyo University Teaching Hospital Sokoto

Tel:08035978720 Email: daliyu55@gmail.com

\section{ABSTRACT}

Background:

Tracheostomy is an important life saving surgical procedure in airway management though often hazardous in emergency setting. Currently its role has been changing due to a rapidly ongoing improvement of intensive care medicine.

The present study aimed to describe our ten years experiences with tracheostomy, evaluate the incidence, indications, complications and to compare our results with those in other part of the world.

\section{Method:}

This was a cross-sectional study of 74 patients who had tracheostomy at our otorhinolaryngology facility of the Usmanu Danfodiyo University Teaching Hospital Sokoto, Nigeria from May 2000 and April 2010. Data's extracted from our theatre records were age, sex, indications, complications and the results were compared with similar work in other part of the world.

\section{INTRODUCTION}

$\mathrm{T}$ racheostomy is the surgical creation of a stoma at the skin surface which leads into the trachea. It is often used interchangeably with the term tracheotomy which is the surgical opening of the trachea. Tracheostomy is an important life saving procedure in many medical conditions that is widely accepted due to its more specific indications. The surgical procedure of tracheotomy is actually a very ancient one. The procedure was portrayed on Egyptian tablets dating back to 3600 BC. The earliest known references to tracheostomy are made in the "Rig veda" a sacred Hindu book published around 2000 $\mathrm{BC}^{1,2}$. At that period it was an extremely dangerous surgical procedure and was undertaken with a good deal of trepidation on the part of both the surgeon and patient. Chevalier Jackson, at the beginning of the twentieth century (1923) described the principle of the procedure in the placing of tracheostomy below the first tracheal ring which has remained to the present day ${ }^{1}$. Although in recent years its role has been changing due to rapidly ongoing improvement in intensive care medicine especially the endotracheal tube technology yet it is a procedure that is not devoid of complications.

In the past, the most frequent indications for tracheostomy widely reported in medical literatures was that of upper airway obstruction secondary to trauma and / or infection. However, in recent years prolonged intubation that necessitates mechanical ventilation tends to be among the commonest indication due to significant high rate of complications that have been observed in prolonged intubation of more than ten days ${ }^{3,4}$. And preoperatively in some major surgeries involving head and neck region where airway compromise is eminent, tracheostomy is indicated.

Several studies have reported the advantages of tracheostomy over prolonged Translaryngeal intubations to includes, lower risk of laryngeal injury, improved comfort for the patient, facilitated weaning from mechanical ventilation, improving pulmonary toilet, enhancing patient communication and decreased sedative requirement. ${ }^{5,6}$

Even though tracheostomy is a life saving procedure, numerous complications associated with it have been observed. Complication rates associated with tracheostomy have been reported in literature to range from 6 to 66 percent and the mortality rate related to tracheostomy is reported to be less than $2 \%{ }^{7}$. However with a carefully performed procedure and a meticulous post-operative management, these complications can be avoided. 
This study tend to evaluate the common indications and pattern of complications of tracheostomy in a tertiary health institution and to compare results with findings from other centers.

\section{MATERIALSAND METHOD}

This was a cross-sectional study. Universal sampling was used to recruit all the 74 patients who presented to our Ear, Nose and throat facilities of the Usmanu Danfodiyo University Teaching Hospital, Sokoto who had tracheostomy performed over the study period (1st May 2000 and $30^{\text {th }}$ April 2010). The clinical charts of these patients were retrieved from the hospital medical records and data's extracted were the demographic profile, indication for tracheostomy, surgical technique, tracheostomy timing (emergency or elective) and complications. The results were analyzed using spss statistical soft ware version 17.

\section{RESULTS}

Seventy four patients had tracheostomies within the ten years span. Age ranges between 7 months and 70years, with a mean age of $30.4 \pm$ standard_deviation years. The rate of tracheostomy was highest among the under 10 years of age (36.5\%) followed by 41-50 years age $(16.2 \%)$ group.(Table I). Males were $51(68.9 \%)$ and $23(31.1 \%)$ females giving a male to female sex ratio of 2.2: 1. Forty seven tracheostomies $(63.5 \%)$ were performed as emergency and $27(36.5 \%)$ as elective procedures. Majority of these patient 51(68.9\%) had temporary tracheostomy and 23(31.1\%) permanent tracheostomy as part of their treatment. Upper airway obstruction secondary to head and neck tumours in 50(67.6\%) of patients was the commonest indication for tracheostomy followed by trauma $16(21.6 \%)$ (Table II). Transverse skin incision was employed in all the cases. Postoperative complications seen were stoma granulation $4(23.5 \%)$, stoma infection $6(35.3 \%)$, tracheal stenosis 2(11.8\%), accidental dislodgement 3(17.6\%) and surgical emphysema $2(11.8 \%)$ with a complication rate of $22.9 \%$ (figure I). Successful decannulation was performed in 51(68.9\%) while decannulation was not done in $23(31.1 \%)$ patients with upper airway malignancy that needed permanent tracheostomy for palliative management. Mortality rate was $8.1 \%$ overall and was due to their underlying pathology. None of the patients had tracheostomy related mortality. Follow up was uneventful.

\section{DISCUSSION}

The surgical procedure of tracheostomy is actually a very ancient one, yet it remains an important life saving procedure in airway management till date..$^{1-4}$

In our study, the highest rate of tracheostomy was $36.5 \%$ of patients below 10 years of age (table I). Foreign bodies in the airway closely followed by recurrent respiratory papillomatosis were the major indicatications for tracheostomy in this age group. Similar study done by Orji in southeast Nigeria reported highest rate in age group 0-20years as against 0-10years in studies conducted in southwestern Nigeria ${ }^{.8,}$ 9 , 10 While a work in northwest Tanzania reported highest rate in third decade ${ }^{11}$. It is therefore imperative that public health education should not only be limited to parents and care givers but schools, media, local community leaders and health professionals should be employed in this campaign on the dangers of foreign body aspiration in children.

In the present review, males were more affected $68.9 \%$ and this may be due to their vulnerability to some hazardous jobs which they undertake in this region for livelihood. In addition their increase susceptibility to some head and neck malignancies especially laryngeal carcinoma, could explained the male preponderance. The indications of tracheostomy are diverse and changing especially over the past two decades ${ }^{10-13}$. In the past relief of upper airway obstruction due to infective conditions were the commonest cause of tracheostomy but with the advent of sensitivity antibiotics and improvement in intensive care medicine a rapid decline was noted. ${ }^{1}$ 5, 13. The commonest indications in our study are head and neck tumors $50(67.6 \%)$, trauma $16(21.6 \%)$ and difficult intubation $5(6.7 \%)$ in that order Table II. These is at variance with works done from southeastern and southwestern Nigeria were the three most commonest indications was laryngeal carcinoma (25\%), foreign body aspiration (21.1\%), bilateral vocal cord paralysis $(9.6 \%)$ and Trauma (34.1\%), infection (29.5\%), laryngeal carcinoma (11.4\%) respectively and might be due to differences in categorization of indications and patient populations $^{8,10}$. The sociocultural life style of these three regions of our country differs significantly and might play a major role in the variances noted. Foreign body 
aspiration $16.2 \%$ and laryngeal pappilomatosis $14.2 \%$ were the commonest indications for tracheostomy in the first decade of life among the paediatric patients in our series and this agrees with studies done in other centers ${ }^{11,14-16}$. There is the need to foster health education to care givers on the deadly hazards associated with foreign body aspiration. The high incidence of 1 aryngeal pappilomatosis in our series could be because of mother to child transmission of Human papilloma Virus (HPV) during delivery. However research need to be done in this area to confirm this observation, public awareness to mothers on the benefits of antenatal cares should be advocated strongly in all tiers of health institutions and more especially at the community level. More over there is a significant increase of laryngeal carcinoma ( $46 \%$ of all head and neck tumours) in our study that are managed by tracheostomy as compared with studies in western part of this country which reported $21.9 \%$ and $25 \%$ in the eastern part ${ }^{8-10}$.In agreement with these studies the reason for the rise is uncertain but may be related to literacy level and late presentation or probably the incidence is high in our society ${ }^{1,18}$. It is therefore imperative that further studies need to be carried out in our setting to further elucidate this observation. Interestingly, difficulty in intubation was the third commonest indication of tracheostomy in our series after head and neck tumours and trauma respectively. (Table II). This is because during the period under review, our center was not adequately equipped with fiber optic endoscopic facilities for intubation.
It is noteworthy that this reason led to the recent revolutionarisation of the center with state of the art fiber optic facilities for intubation.

this reason led to the recent revolutionarisation of the center with state of the art fiber optic facilities for intubation.

In our entire patient, a vertical skin crease incision was the surgical technique employed in both elective and emergency situation. This is preferred in our center over the vertical midline skin incision because of the advantage of a better cosmetic outcome, even though the vertical midline skin incision has the advantage of running in the line of trachea and reported to be less vascular $^{1,8-11}$. Other technique such as the percutaneous dilatation tracheostomy is being advocated for its cost effectiveness and reduced operation time over the open surgical tracheostomy ${ }^{20}$. Facilities to carry out this innovation is lacking in our center especially in the adult patient, since it is reported to be a dangerous procedure in children and young adult ${ }^{1}$.

The present study revealed that $63.5 \%$ of our patient had tracheostomy done as an emergency procedure and $36.5 \%$ as elective, which is similar to the findings in studies done in southeastern Nigeria with $94.2 \%$ as emergency and 5.4\% elective ${ }^{14}$. While study in southwestern Nigeria reported $62.5 \%$ emergency and $37.5 \%$ elective $^{10}$ also a similar study in Tanzania reported $80.4 \%$ emergency and $19.6 \%$ elective $^{21}$.

Tracheostomy as a life saving procedure is not bereft of complications. Complication rate as reported in literature have a wide range (6-66\%) with a mortality of less than $2 \%^{1,21}$. The post-operative complications observed in this study are shown in figure I. the rate of postoperative complication is $22.9 \%$ which is lower than what was reported by other centers in Nigeria with $45.5 \%$ from the west and $40.4 \%$ from the east ${ }^{8,10,14}$. However the late presentation of most of these patients with upper airway obstruction necessitated an emergency tracheostomy in our study and this accounted for this complication rate.

The two most common complications in our study were stoma infection $35.3 \%$ and stoma granulation $23.5 \%$ (Fig I). The culture result from the stoma swab from this patient yielded pseudomonas auriginosa commonly and sensitivity antibiotic were used to combat the infections while those with stoma granulation had it excised and decannulation was uneventful. Surgical emphysema $11.8 \%$ resolved on the 4 th to 6 th day post operatively. Accidental decannulation occurred in 3(17.6\%) of our patient which was due to an inappropriately secured tube. Complication rates associated with tracheostomy can be prevented by good surgical technique and meticulous postoperative care. ${ }^{22-24}$.

In $68.9 \%$ of patient who had temporary tracheostomy, decannulations were effected successfully following the resolution of the cause of upper air way obstruction.

The overall mortality recorded in this study was $6(8.1 \%)$ and this was from underlying pathology as all of them presented late with head and neck malignant conditions. This is 
higher when compared to findings in other center in Nigeria while similar study in Tanzania recorded a $13.6 \%$ mortality rate ${ }^{11}$. In this series no tracheostomy related death was recorded which agrees with findings in other centers indicating an improvement of skilled trained otolaryngologist and the availability of facilities in our intensive care units. This is a single center retrospective review of the experience of four otorhinolaryngologists. To determine a national incidence of tracheostomy, a prospective population study is hereby advocated.

\section{CONCLUSION:}

Head and Neck tumours as a cause of upper airway obstruction remain the most common indication of tracheostomy in our center. Despite the number of complications associated with this procedure, its life saving role in airway management is still relevant in our center. With careful and precise surgical technique and postoperative care, complication can be minimized.

Further research on other newer techniques such as the percutaneous dilatation tracheostomy is hereby recommended.

\section{REFERENCES:}

1. Paul Pracy, upper airway obstruction and tracheostomy. In: Michael G, Ray C, (eds). ScottBrowns otorhinolaryngology, Head and Neck Surgery. 7th Ed. Hodder Arnold 2008; 22862303.

2. Pahor A.L: Ear, nose and throat in Ancient Egypt, Journal of Laryngology and Otology, 1992;
106(9): 773-779.

3. Butnaru CS, Colreavy MP, Ayari S, Froehlich P, Tracheostomy in children: evolution in indications, Int. Pediatr. Otorhinolaryngol, 2006; 70(1): 115-9.

4. Feldmann H, Treatment of acute and chronic laryngeal and tracheal stenoses in the 19th and beginning of the 20th century by tracheotomy, craniotomy, intubation and dilatation. Laryngorhinootol, 1995; 74: 216-222.

5. Hadi A, Ikram M: Upper airway obstruction: Comparison of tracheostomy and endotracheal intubation. PJLO 1995; 11:25.

6. Nieszkowska A,Combes A, Luyt $\mathrm{CE}$ et al. Impact of tracheotomy on sedative administration, sedative level, and comfort of mechanically ventilated intensive care unit patients. Crit Care Med 2005; 33:207-253.

7. Kollef MH, Ahrens TS, Shannon $\mathrm{W}$ : Clinical predictors and outcomes for patients requiring tracheostomy in the intensive care unit. Crit Care Med 1999, 27:1714-1720.

8. Amusa YB, Akinpelu VO, Fadiora SO, Agbakwuru EA. Tracheostomy in surgical practice:experience in a Nigerian tertiary hospital. West Afr J Med. 2004; 23(1):32-4.

9. Orji FT, Ezeanolue BC. Update on the pattern of tracheostomies at a tertiary health institution after 27 years. Niger. J.Otolaryngol. 2006;3(1): 8-15.

10.Eziyi J A, Amusa Y B, Musa I O, Adeniji A O, Olarinoye $\mathrm{O} \mathrm{T}$, Ameye SA, Adeyemo A:
Tracheostomy in south western Nigeria: Any change in pattern? Journal of Medicine and Medical Science 2011;2(7): 997-1002.

11. Japhet M G, Darius D B, Phillipo L C: Ten-year experiences with Tracheostomy at a University teaching hospital in Northwestern Tanzania: A retrospective review of 214 cases. World Journal of Emergency Surgery 2011, 6:38.

12. Primuharsa PSH, Wong CY, Hazim MY, Megat Shiraz MA, Goh BS: Pediatric tracheostomy in Hospital University Kebangsaan Malaysia- a changing trend. Med J Malaysia 2006; 61(2):209-13. PubMed Abstract

13.Alladi A, Rao S, Das K, Charles AR, Cruz AJ: Pediatric tracheostomy: a 13 year experience. Pediatr Surg Int 2004; 20(9):695-8.

14. Orji FT, Ezeanolue BC. Update on the pattern of tracheostomies at a tertiary health institution after 27 years. Niger. J.Otolaryngol. 2006; 3(1): 8-15.

15..Adoga AA, Ma'an ND: Indications and outcome of pediatric tracheostomy: results from a Nigerian tertiary hospital. BMC Surgery 2010, 10:2.

16. Onotai LO, Etawo US. An audit of paediatric tracheostomies in Port Harcourt Nigeria. International Journal of Medicine and Medical Sciences 2012; 2 (7): 148-153.

17. Okoye BCC: Tracheostomy in Port Harcourt. Nig J Surg Sci 2000, 10:99-102.

18.Mohammad A R, . Shazibur 
Rashid, Kamruzzaman M S, Khabir U A. :Tracheostomy in head-neck malignancy. Bangladesh J Otorhinolaryngol 2010; 16(2): 120-125.

19.Kremer B, Botos-Kremer AI, Eckel HE, Schlorndoff G: Indications, complications and surgical techniques for pediatric tracheostomies. J Pediatr Surg 2002, 37(11):1556-62.

20.Heikkenen M, Aarnio P, Hannukainen J. Percutaneous dilational tracheostomy or conventional surgical tracheostomy. Crit Care Med 2000; 28: 1399-1402.

21. Kodiya AM, Afolabi AO, Grema US, Ajayi IO, Ngamdu YB, Labaran SA: Tracheostomy in Northern Nigeria - A multicenter Review. East and Central Afri. J Surg 2013, 18(1): 65-70.

22. Asmatullah, Inayatullah, Rasool G, Billah M : C o m p l c a t i o n o f emergency tracheostomy. J Postgrad Med Inst 2004, 18(2):225-9.

23. Khan FA, Ashrafi SK, Iqbal H, Sohail Z, Wadood: Operative complications of tracheostomy. Pak J Surg 2010, 26(4):308-310.

24. Onakoya PA, Nwaorgu OG, Adebusoye LA: Complications of classical tracheostomy and management. Trop Doctor 2003, 33:148-150.

25.Fasunla JA, Aliyu A, Nwaorgu O G B, I j a d u o l a G T A : Tracheostomy Decannulation: Suprastomal Granulation Tissue in Perspective. East Centr Afr J Surg 2010, 15(1):81-85.

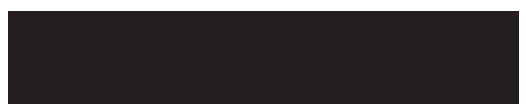

TABLE I: AGE AND SEX DISTRIBUTION.

\begin{tabular}{ccccc}
\hline Age(years) & males & females & total & \% of total \\
\hline 0 -10 & 17 & 10 & 27 & 36.5 \\
$11-20$ & 3 & 3 & 6 & 8.1 \\
$21-30$ & 1 & 4 & 5 & 6.7 \\
$31-40$ & 4 & 3 & 7 & 9.5 \\
$41-50$ & 9 & 3 & 12 & 16.25 \\
$51-60$ & 9 & - & 9 & 12.2 \\
$61-70$ & 8 & - & 8 & 10.8 \\
TOTAL & 51 & 23 & 74 & 100 \\
\hline
\end{tabular}

TABLE II: INDICATIONS FOR TRACHEOSTOMY

\begin{tabular}{|c|c|c|c|}
\hline Indications & & frequency & percentage \\
\hline \multicolumn{4}{|c|}{ A. Upper airway obstruction: } \\
\hline \multirow[t]{4}{*}{1.} & Infection & & \\
\hline & Retropharyngeal abscess & 1 & \\
\hline & Croup & 2 & \\
\hline & Total & 3 & 4.1 \\
\hline \multirow[t]{6}{*}{2.} & Trauma: & & \\
\hline & Airway burns & 2 & \\
\hline & Cut throat & 1 & \\
\hline & Foreign body aspiration & 12 & \\
\hline & $\begin{array}{l}\text { Tracheomalacia ( post } \\
\text { Thyroidectomy) }\end{array}$ & 1 & \\
\hline & Total & 16 & 21.6 \\
\hline \multirow[t]{7}{*}{3.} & Tumours & & \\
\hline & Pappilomas & 11 & \\
\hline & Laryngeal carcinoma & 23 & \\
\hline & Oropharyngeal carcinoma & 12 & \\
\hline & Thyroid carcinoma & 2 & \\
\hline & Nasopharyngeal carcinoma & 2 & \\
\hline & Total & 50 & 67.6 \\
\hline
\end{tabular}

B. Adjunct for Head and Neck sugeries :

1. Difficult intubation in

Temporomandibular joint

Ankylosis

Ameloblastoma

Olfactory Neuroblastoma

3

1

Total 5

6.7

GRAND TOTAL $\mathbf{n}=74 \quad \mathbf{1 0 0} \%$

Figure I: post-operative complications

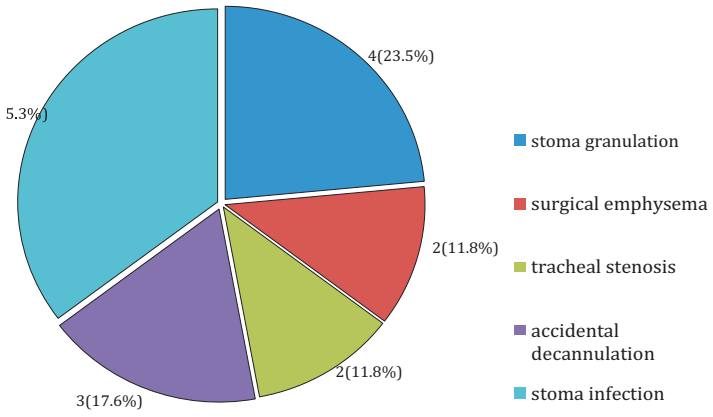

